\title{
Protein tyrosine phosphatase 1B is located with glucagon vesicles, and its concentration is inversely correlated with the rate of glucagon secretion of INR1G9 cells
}

\author{
M Wimmer ${ }^{1}$, C Tag ${ }^{1}$, D Schreiner ${ }^{2}$ and $\mathbf{H}$ W Hofer ${ }^{2}$ \\ ${ }^{1}$ University of Giessen, Institute of Anatomy and Cell Biology, D-35385 Giessen, Germany \\ ${ }^{2}$ University of Konstanz, Department of Biology, D-78547 Konstanz, Germany \\ (Requests for offprints should be addressed to M Wimmer; Email: Monika.Wimmer@anatomie.med.uni-giessen.de)
}

\begin{abstract}
High concentrations of protein tyrosine phosphatase (PTP) were found with secretory vesicles of glucagon-producing INR1G9 cells by electron microscopic immunocytochemistry, using a polyclonal antiserum specific for the PTP1B/T-cell (TC)PTP subfamily of PTP. Since TCPTP protein and mRNA were below the detection limit in the cells but significant amounts of PTP1B and mRNA were recognised by a specific monoclonal antibody and a mRNA probe we conclude, that the PTP associated with the vesicles is PTP1B. Only reverse transcriptase (RT)-PCR with primers specific for PTP1B
\end{abstract}

yielded a product of the expected nucleotide sequence. Thus, we conclude that the PTP associated with the vesicles is PTP1B. The presence of vanadate for $48 \mathrm{~h}$ attenuated PTP1B expression and caused reduction of steady-state levels of the phosphatase. These conditions also led to a continuing increase in the steady-state rate of glucagon release by the cells. This rate and tyrosine phosphatase levels showed an inverse relationship, suggesting a suppressive role of $\mathrm{PTP} 1 \mathrm{~B}$ on the regulated secretion of glucagon by INR1G9 cells.

Journal of Endocrinology (2004) 181, 437-447

\section{Introduction}

The secretory vesicles of glucagon-secreting cells of Langerhans islets of the pancreas contain high amounts of a protein exhibiting immunoreaction with an antiserum raised against the conserved $\mathrm{N}$-terminal part of protein tyrosine phosphatase (PTP) of the $\mathrm{PTP} 1 \mathrm{~B} / \mathrm{T}-\mathrm{cell}$ (TC)PTP family (Wimmer et al. 1999). The immunoreaction was confined to secretory vesicles, thus suggesting a potential, but so far undefined role, of the PTP in the function of these vesicles.

Insulin-producing cells did not react with this antiserum. On the other hand, it has been reported that other proteins that are structurally related to transmembrane tyrosine phosphatase, namely, ICA512/IA-2 and phogrin/IA-2 $\beta$ (Kawasaki et al., 1996, Payton et al. 1995, Cui et al. 1998), are major autoantigens involved in the generation of insulin-dependent diabetes mellitus (reviewed by Pietropaolo et al. 1997, Zanone et al. 2003). These proteins are present not only in pancreatic B-cell secretory granules but also on neurosecretory granules (Dirkx et al. 1998) and human lung cancer cell lines of neuroendocrine phenotype. It has been questioned whether these proteins exhibit PTP activity, but they apparently become phosphorylated (Wasmeier \& Hutton 1999) and cleaved from membranes (Ort et al. 2001) upon stimulation of insulin secretion, and they may be involved in the mobilisation and exocytosis of secretory granules (Wasmeier \& Hutton 2001, Wasmeier et al. 2002). Since involvement of PTP has been discussed not only for pancreatic islets (Gogg et al. 2001) but also for the secretion of gonadotrophin (Marantz et al., 1995) and for the exocytotic process in exocrine pancreatic acinar cells (Feick et al. 1998, 1999), tyrosine dephosphorylation may be a rather general signal transducing mechanism in protein secretion. The presence of tyrosine phosphatases of distinct subfamilies in islet cells which secrete either glucagon or insulin would indicate different types of tyrosine dephosphorylation mechanisms involved in secretion of these hormones.

To avoid the cellular heterogeneity of pancreatic islets, we used INR1G9 cells derived from a hamster glucagonoma (Takaki et al. 1986) for the present study. This cell line is well characterised by stable basal secretion of glucagon and has been used in studies of proglucagon processing (Mineo et al. 1995, Dhanvantari \& Brubaker 1998) and calcium oscillations (Drucker et al. 1988, Bode et al. 1994, 1999). The cells display ultrastructure similar to that of native A cells of islets, and they reacted with the antiserum against PTP1B/TCPTP in the same way as pancreatic A cells. Thus, the cell line seems to be an appropriate tool for studying the mechanisms of glucagon 
secretion. Here we show the localisation of PTP1B with secretory vesicles of INR1G9 cells. We also demonstrate that treatment of the cells with low concentrations of vanadate for $48 \mathrm{~h}$ leads to reduced expression of PTP1B, and that attenuation of tyrosine phosphatase activity caused by vanadate treatment is correlated with strong stimulation of glucagon secretion.

\section{Materials and Methods}

\section{Materials}

INR1G9 cells, a generous gift from Dr U. Wulbrand (Department of Medicine, Philipps-University, Marburg, Germany), were cultured in RPMI 1640 medium supplemented with $10 \%$ fetal calf serum (FCS), 1\% penicillin/ streptomycin at $37{ }^{\circ} \mathrm{C}$ in the presence of $5 \% \mathrm{CO}_{2}$. For electron microscopic examination, INR1G9 cells were fixed in $2 \%$ paraformaldehyde $/ 0 \cdot 25 \%$ glutardialdehyde and embedded in Unicryl (Polyscience, Eppelheim, Germany).

The antisera against TCPTP/PTP1B used for immunocytochemical demonstration as well as for immunoblots were raised in rabbits against a $35 \mathrm{kDa} \mathrm{N}$-terminal fragment of human TCPTP (Cool et al. 1989) comprising the catalytic domain (amino acids 1-319) expressed in E. coli (Schmid et al. 1996, Wimmer et al. 1998). Monoclonal antibodies selective for TCPTP (Cat. no. PH03L) and PTP1B (Cat. no. PH02) were purchased from Oncogen Research. The guinea pig antiserum against glucagon was purchased from Biotrend (Cologne, Germany). Specificity of antibodies against tyrosine phosphatases was checked with His6-fusion proteins of PTP1B and TCPTP expressed with $\mathrm{pQE30}$ vectors (Qiagen) in the E. coli strain AD202 and purified by Ni-agarose chromatography.

\section{Immunocytochemistry}

Immunocytochemical staining was performed according to a standard protocol either with cells fixed on the culture slide or with ultrathin sections of the Unicryl-embedded cells. Double immunostaining was done with an antibody to TCPTP/PTP1B (1:250) in combination with an antibody to glucagon $(1: 2000)$ or to synaptophysin $(1: 250)$ as indicated. Anti-PTP was detected by gold-conjugated secondary goat antibody to rabbit $\operatorname{IgG}$ (particle size $10 \mathrm{~nm}$; British Biocell, Cardiff, UK), and anti-glucagon was visualised by gold-conjugated secondary goat antibody to guinea pig IgG (particle size $20 \mathrm{~nm}$; British Biocell). For double staining with synaptophysin, anti-PTP was marked by $20 \mathrm{~nm}$ gold particles, while anti-synaptophysin was detected by gold-conjugated antibody to mouse IgG (particle size $10 \mathrm{~nm}$ ). Contrast enhancement was achieved by treatment with $5 \%$ uranyl acetate.

Monoclonal antibodies to TCPTP and to PTP1B were used in 1:125 dilution for light microscopic immunocytochemistry. Both reactions were visualised by fluorescein isothiocyanate (FITC) conjugated to antibodies raised against mouse $\operatorname{IgG}(1: 80)$.

\section{Biochemical analysis}

PTP activities were determined after homogenisation of the cells in buffer I $(50 \mathrm{mM}$ triethanolamine- $\mathrm{HCl}, \mathrm{pH} 7 \cdot 5$, $15 \mathrm{mM}$ 2-mercaptoethanol, aprotinin $2000 \mathrm{units} / \mathrm{ml}$, and pepstatin $10 \mu \mathrm{M})$ in a glass homogeniser. The supernatant was separated from the pellet by centrifugation $(23000 \boldsymbol{g}$, $10 \mathrm{~min}$ ), and the pellet was re-extracted, first with buffer $\mathrm{I}$ and then twice with buffer I containing 1\% Triton X-100.

\section{Enzyme assay}

PTP assays were performed in $50 \mathrm{mM}$ triethanolamine$\mathrm{HCl}(\mathrm{pH} 7 \cdot 5)$ containing $15 \mathrm{mM}$ 2-mercaptoethanol, $0 \cdot 1 \%$ Triton X-100, bovine serum albumin $(1 \mathrm{mg} / \mathrm{ml})$ and $4 \mu \mathrm{M}$ reduced, maleylated and carboxymethylated lysozyme (Tonks et al. 1988) labelled with ${ }^{32} \mathrm{P}$ on tyrosine (Batzer et al. 1990) at $22^{\circ} \mathrm{C}$ in a volume of $40 \mu \mathrm{l}$.

After $15 \mathrm{~min}$ of incubation, the reactions were terminated by addition of an equal volume of $20 \%$ trichloroacetic acid. The samples were spun in an Eppendorf microcentrifuge, and $40 \mu \mathrm{l}$ of the supernatant were added to $1 \mathrm{ml} \mathrm{H}_{2} \mathrm{O}$ for Cerenkov counting. The assay procedure was developed for PTP of the PTP1B/TCPTP subfamily (Tonks et al. 1988) but shows low activities for the enzymes of the SH-PTP subfamily (A Voges, PhD thesis, University of Konstanz, 2003).

\section{Immunoblotting}

Samples were separated on a 10\% SDS-PAGE gel. Transfer on an Immobilon P membrane (Millipore, Bedford, MA, USA) was performed according to Towbin et al. (1979). The membrane was blocked with $10 \%$ fat-free milk powder in PBS and subsequently incubated for $1 \mathrm{~h}$ with antibodies diluted in the $0.5 \%$ fat-free milk powder in PBS. Incubation with monoclonal anti-PTP1B or anti-TCPTP was done overnight at $4{ }^{\circ} \mathrm{C}$. Alkaline phosphatase-conjugated anti-mouse immunoglobulins were applied for $1 \mathrm{~h}$ at room temperature, and the reaction was visualised with the SigmaFast BCIP/NBT substrate. A mixture of prestained molecular weight markers (BioRad Low Range and Invitrogen SeeBlue) was used for calibration.

\section{RT-PCR}

RNA was prepared from $200 \mu \mathrm{g}$ INR1G9 cells frozen in liquid nitrogen using the Roti-Quick Kit (Roth, Karlsruhe, Germany). An amount of $3.4 \mu \mathrm{g}$ mRNA was reverse-transcribed with 40 units $\mathrm{M}-\mathrm{MuLV}$ reverse 
transcriptase (MBI Fermentas, Riga, Latvia) in the presence of $1 \mathrm{mM}$ dNTP and 20 pmol specific reverse primer in a total volume of $20 \mu \mathrm{l}$.

Reactions were performed for $60 \mathrm{~min}$ at $37^{\circ} \mathrm{C}$ followed by inactivation of the enzyme at $72{ }^{\circ} \mathrm{C}$ for $10 \mathrm{~min}$. PCR was performed with either Pfu-polymerase (Promega) or Taq-polymerase (Peqlab, Erlangen, Germany), using $1 \mu \mathrm{l}$ reverse transcriptase reaction product, 12 pmol specific forward and reverse primers, and $0.2 \mathrm{mM}$ dNTP in a total volume of $50 \mu \mathrm{l}$ through 30 cycles of $30 \mathrm{~s}$ at $94^{\circ} \mathrm{C}, 30 \mathrm{~s}$ at $57^{\circ} \mathrm{C}$ and $2 \mathrm{~min}$ at $72^{\circ} \mathrm{C}$ for Pfu-polymerase or $1 \mathrm{~min}$ for Taq-polymerase in a Biometra thermocycler (Göttingen, Germany). The forward and reverse primers were chosen for conserved regions of PTP-1B and TC-PTP, using Windows 32 PrimerSelect - Lasergene DNASTAR software. The following primers were used: for PTP-1B: forward, 5'-TGGGAACTGGGCGGCTATTAC-3', and reverse, 5'-TCCACTGATCCTGCACTGACGAG-3'; for TCPTP: forward, 5'-ACCATCGAGCGGGAG TTC-3', and reverse, 5'-ATCTTGGCCTTTTTCTTT TTCGTTCAGTTT-3'.

The PCR products were purified from agarose gel using an extraction kit (Machery \& Nagel, Düren, Germany) and ligated into pCR-Script plasmid. Sequencing of DNA inserts was done by SeqLab (Göttingen, Germany) with $\mathrm{T} 3$ and $\mathrm{T} 7$ primers.

Additional PCR reactions were done, using the Taq polymerase protocol to check for the presence of transcripts SHPTP1 and SHPTP2 with the following primers: for SHPTP1, 5'-CGGAATTCCACCGAGACCTCAG TGGGCTGGAT-3' and 5'-CGGAATTCCTCAGGG CTGAGGCATGGCCACCTG-3'; for SHPTP2, 5'-CG GAATTCATATGACATCGCGGAGATGGTTTCAC CC-3' and $5^{\prime}$-GGAATTCATCTGAAACTTTTCTGC TGTTGCATCAGGCC-3'.

This protocol was also used for quantitation, using the following primers for glyceraldehydephosphate dehydrogenase: $\quad 5^{\prime}$-GCCAGGGTTTCCATGAAATGAGC-3' and 5'-TCAGAGTGGAGGAGGGCCATTC-3'.

\section{Northern blotting}

An amount of $10 \mu \mathrm{g}$ RNA, prepared as described above, was separated on $1 \%$ agarose gels in the presence of formaldehyde and formamide according to Lehrach et al. (1977), blotted to positively charged nylon membrane (Boehringer, Mannheim, Germany), and fixed by $5-\mathrm{min}$ irradiation with UV-light $(285 \mathrm{~nm})$. Hybridisation with digoxigenin-labelled probes was done in Dig-Easy-Hyb buffer (Boehringer) at $62{ }^{\circ} \mathrm{C}$ and $65^{\circ} \mathrm{C}$ for $12 \mathrm{~h}$. The DIG Wash and Block buffer set (Boehringer) was used for the subsequent washing steps. The blots were repetitively used after stripping with formamide $(50 \%)$ and SDS (1\%) in 50 mM Tris- $\mathrm{HCl}(\mathrm{pH} 8 \cdot 1)$.

The antisense probes recognised coding porcine mRNA base segments 1-1311 for TCPTP, 106-1260 for PTP1B,
318-1385 for PTP1C and 1-1749 for PTP1D porcine proteins (R. Simpfendorfer \& H.W. Hofer, unpublished). They were synthesised with RNA polymerase T3 or RNA polymerase T7 respectively and labelled with digoxigenin with the DIG RNA Labelling Mix (Boehringer). Purity and labelling of the probes were checked by electrophoresis and immunoblotting. Chemiluminescent detection of blots employed antidigoxigenin-AP Fab fragments (Boehringer) and CSPD (Roche). The lanes on films were scanned, and the intensity of bands was evaluated with the ScanPack II program (Biometra, Göttingen, Germany). The amount of $18 \mathrm{~S}$ rRNA was used as an internal standard.

\section{Determination of glucagon secretion}

Cells were grown to confluence as described above. For the determination of the glucagon secretion rate, the medium was replaced by Hanks' balanced salt solution, and the cells were incubated for $30 \mathrm{~min}$. The supernatant was collected, and the concentration of glucagon was determined by a standard RIA method (Biermann, Bad Nauheim, Germany).

\section{Secretion experiments with vanadate or okadaic acid}

The cells were grown to confluence in culture flasks under routine conditions. Then the culture medium was replaced by fresh medium plus vanadate or okadaic acid at the indicated concentrations. After 4 or $24 \mathrm{~h}$ for okadaic acid and $48 \mathrm{~h}$ of incubation with vanadate, the secretion of glucagon during a $30-$ min period was determined as described in the previous paragraph.

\section{Results}

Co-localisation of glucagon and tyrosine phosphatase in secretory vesicles

Immunofluorescence studies confirmed the existence of a tyrosine phosphatase of the TCPTP/PTP1B type colocalised with glucagon in glucagon-producing INR1G9 cells (data not shown). Immunocytochemical analysis of the distribution of PTP and glucagon in the cells at electron microscopic level is shown in Fig. 1. The small $(10 \mathrm{~nm})$ gold particles identify the tyrosine phosphatase, while the bigger $(20 \mathrm{~nm})$ particles represent the localisation of glucagon.

Both proteins were obviously present on or in the immediate vicinity of vesicles. The size of the vesicles in INR1G9 cells was between 140 and $240 \mathrm{~nm}$, and they corresponded in size, shape and intracellular distribution to secretory vesicles of glucagon-secreting alpha-cells in the Langerhans islets of the Syrian golden hamster (Takaki et al. 1986) from which the cells were derived. 
To verify the localisation of PTP on secretory granules, the cells were checked for the co-existence of synaptophysin, an integral membrane protein of secretory
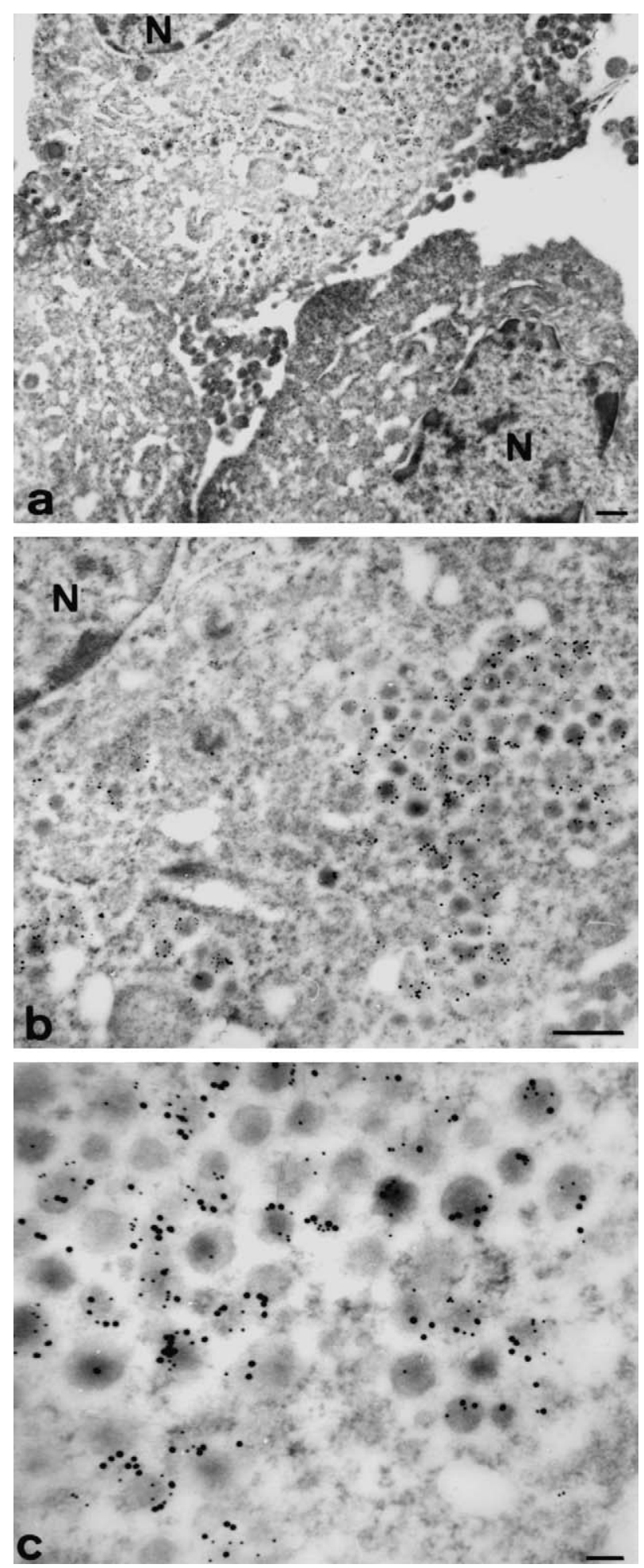

granules, and PTP. Light microscopic examination of double immunofluorescence (Fig. 2a and b), and electron microscopic studies (Fig. 2c) revealed co-localisation of both antigens on secretory granules.

For more information about intracellular localisation of PTP, the cells were probed with an antibody to golgin 97, a protein localised at the cytoplasmic side of the Golgi complex, in combination with the polyclonal antibody to PTP. As shown by Fig. 3, PTP and golgin 97 were co-localised around the nucleus.

\section{Analysis for tyrosine phosphatases in INR1G9 cells}

The polyclonal antibodies used for immunocytochemical analysis were directed against the N-terminal and catalytic domain conserved in PTP1B and TCPTP, and they detected both members of this PTP subfamily. Therefore, commercially available monoclonal antibodies specific for either PTP1B or TCPTP were used for differentiation between the two phosphatases (Fig. 4a and b). Specific recognition of the phosphatases by their respective monoclonal antibodies was verified by in situ hybridisation (Fig. $4 \mathrm{c}$ and $\mathrm{d}$ ) as well as immunoblotting of the bacterially expressed TCPTP and PTP1B after denaturing electrophoresis (Fig. 5a). However, these antibodies, although specific, were not sufficiently sensitive for electron microscopic immunocytochemistry but were useful only for immunofluorescence studies. INR1G9 cells exhibited a distinct reaction with the monoclonal antibody directed against PTP1B (Fig. 4a), whereas the reaction with the monoclonal antibody against TCPTP was at the level of background fluorescence (Fig. 4b). In situ hybridisation assays were in agreement with these observations since they confirmed the presence of mRNA encoding PTP1B, whereas the reaction failed for TCPTP (Fig. 4c and d).

Immunoblotting of proteins in extracts from INR1G9 cells on nitrocellulose membranes with a monoclonal antibody against PTP1B showed a single band of an estimated molecular mass of about $50 \mathrm{kDa}$ (Fig. 5a). Probing of the blots for members of the SH2-domain containing tyrosine phosphatase subfamily (PTP1C and PTP1D or SHPTP1 and 2 respectively) showed negative results.

We also qualitatively checked for the mRNA of PTP1B, TCPTP and the SH2 tyrosine phosphatase subfamily members SHPTP1 and 2 by PCR after reverse

\footnotetext{
Figure 1 Immunocytochemical localisation of PTP and glucagon in ultrathin sections of INR1G9 cells. (a) Overview showing parts of three cells (original magnification $\times 6000$ ). N: nucleus; bar $=1 \mu \mathrm{m}$. (b) Closeup of the cell in the upper left corner of panel a, showing part of the nucleus and the area of secretory vesicles (original magnification $\times 12930$ ). Bar $=0.5 \mu \mathrm{m}$. (c) Area of the secretory vesicles at higher magnification ( $\times 35970)$. PTP is marked by gold particles $10 \mathrm{~nm}$ in size, and glucagon is marked by gold particles $20 \mathrm{~nm}$ in size. Bar $=0 \cdot 1 \mu \mathrm{m}$.
} 

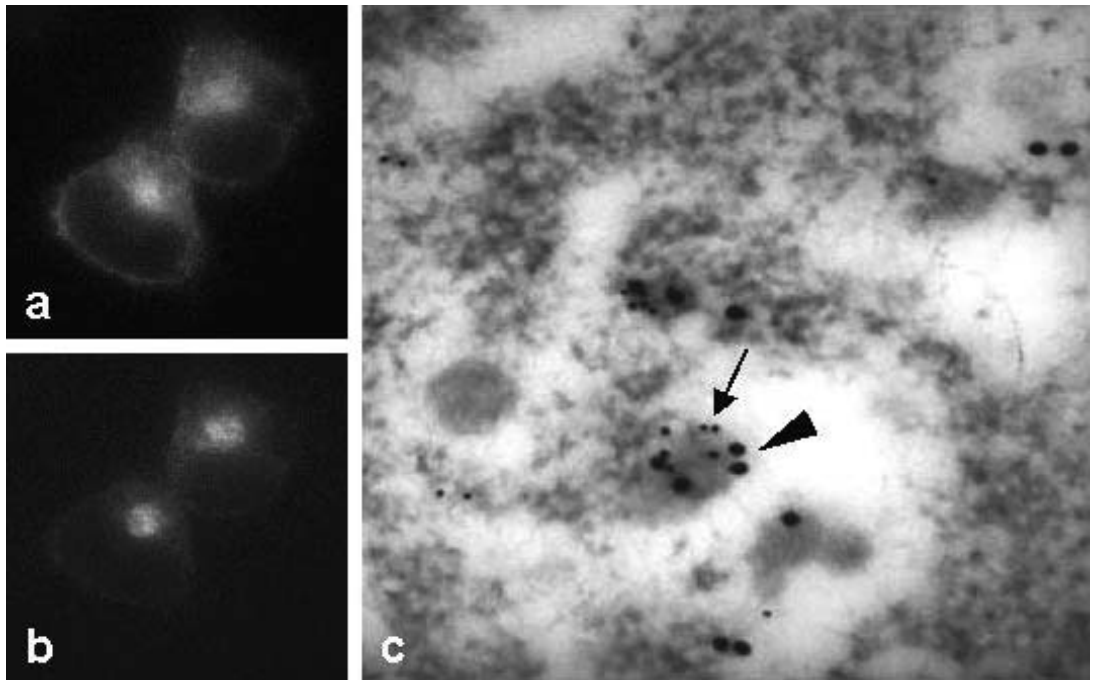

Figure 2 (a) Localisation of PTP in INR1G9 cells demonstrated with the polyclonal antibody. (b) Localisation of synaptophysin in the same cells. (c) Immunocytochemical localisation of PTP and synaptophysin in ultrathin sections of INR1G9 cells. PTP is marked by gold particles $20 \mathrm{~nm}$ in size (arrowhead) and synaptophysin is marked by gold particles $10 \mathrm{~nm}$ in size (arrow). Bar $=0 \cdot 1 \mu \mathrm{m}$.

transcription of the mRNA. Primers derived from the base sequences of highly conserved regions of the corresponding mouse enzymes in the case of PTP1B and TCPTP were used for amplification with proofreading Pfu-polymerase (Fig. 5b). A PCR product of the expected size $(836 \mathrm{bp})$ was obtained with primers for PTP1B, while no amplification product of the expected size (1126 bp; Fig. 5b, arrow) was found for TCPTP with Pfu polymerase.

The PCR product representative for PTP1B was ligated into the pPCRSCRIPT plasmid and sequenced. It encoded 280 amino acids that were $98 \cdot 5 \%$ identical with a corresponding sequence of PTP1B from rat. All four amino-acid exchanges within this region were conservative and confirmed the identity of the PCR product with cDNA encoding hamster PTP1B. While, in contrast to PTP1B, the PCR reaction for TCPTP was negative when $\mathrm{Pfu}$-polymerase was used, the sequence of an amplification
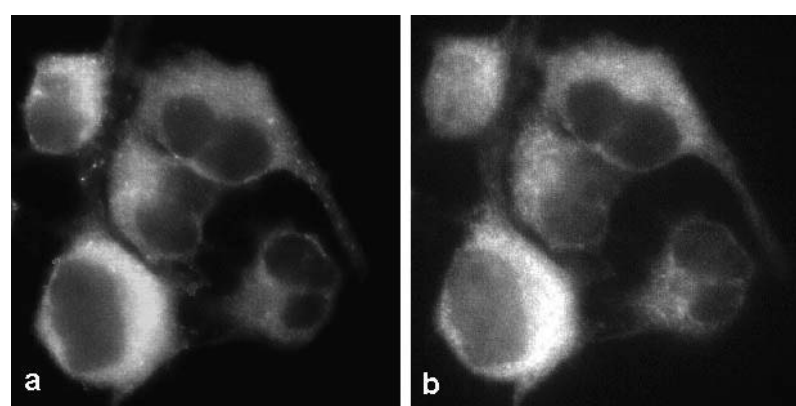

Figure 3 (a) Localisation of PTP in INR1G9 cells. (b) Localisation of golgin in the same INR1G9 cells. product obtained with non-proofreading Taq polymerase was not related to that of a tyrosine phosphatase. Primers for SHPTP1 and SHPTP2 did not even generate detectable amplification products with Taq polymerase (data not shown).

\section{Tyrosine phosphatase and glucagon secretion}

Cultured INR1G9 cells secreted glucagon into the culture medium. The average secretion rate under standard conditions (see Materials and Methods) was about $6 \mathrm{ng}$ per 30 min per $10^{6}$ cells. To check for possible involvement of P-type serine/threonine phosphatases, the secretion rate of the cells was also studied in the presence of either $2 \mathrm{nM}$ or $10 \mathrm{nM}$ okadaic acid, a well-known inhibitor of PP1 and PP2a (Cohen 1989, Cohen et al. 1990). No significant change of the secretion rate was observed after 4 or $24 \mathrm{~h}$ of exposure.

To check for a potential influence of PTP activity on glucagon release, we reduced the activity of the enzyme by the use of PTP inhibitors. Addition of vanadate, a well-known inhibitor of tyrosine phosphatases, to INR1G9 cultures elevated glucagon secretion in a concentration-dependent manner and also decreased the tyrosine phosphatase activity extracted from the cells. Reduced PTP activity in the assays, however, was not due to kinetic inhibition of the enzyme by residual intracellular vanadate because this had undergone more than 1000-fold dilution, but was representative of a decrease in the amount of active phosphatase.

Figure 6a shows the rate of glucagon secretion plotted against extracellular vanadate concentrations to which the 

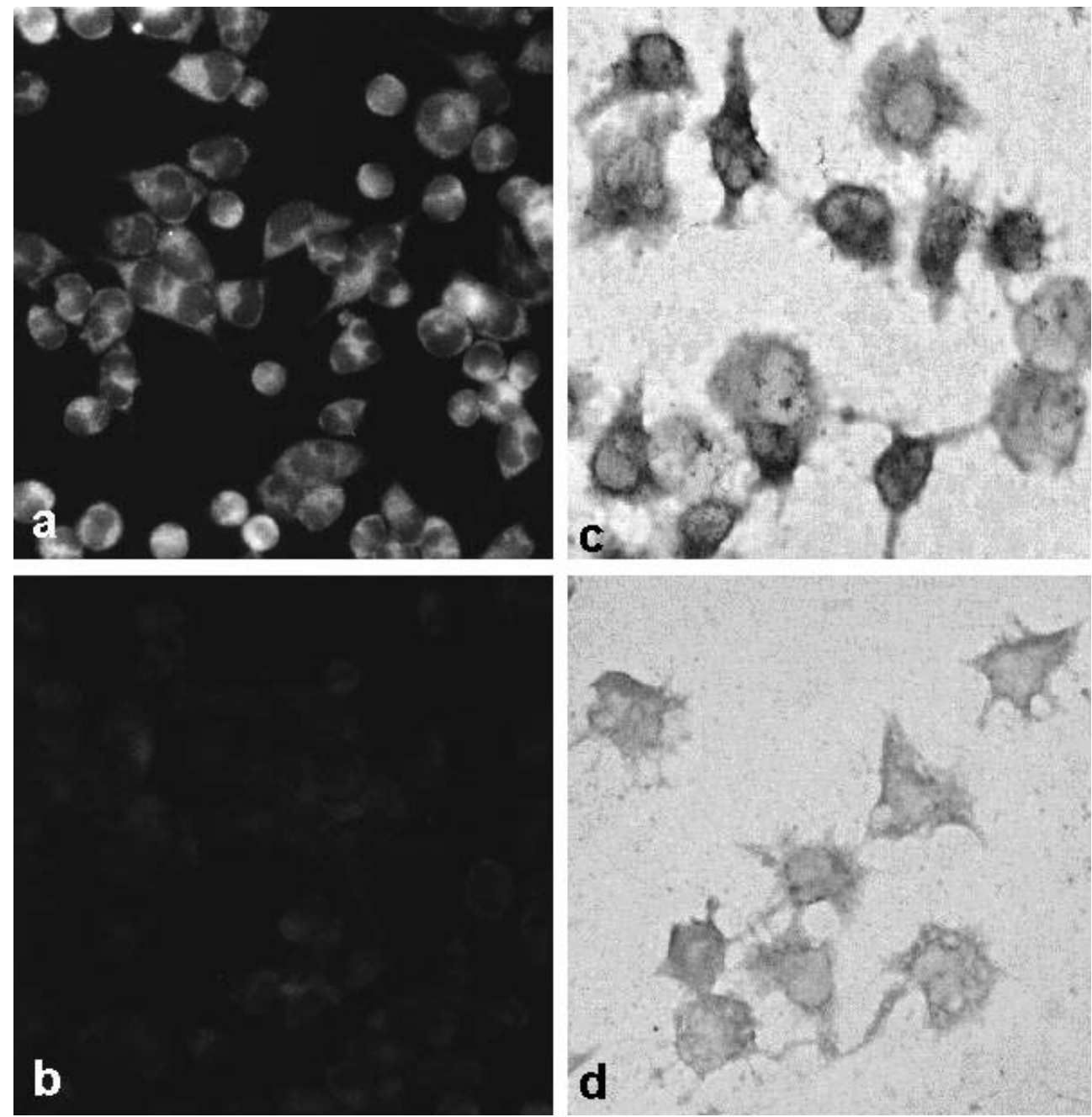

Figure 4 (a) Localisation of PTP1B in INR1G9 cells demonstrated with a specific monoclonal antibody (original magnification $\times 400$ ). (b) Localisation of TCPTP as probed with a monoclonal antibody $(\times 400)$. (c) In situ hybridisation of PTP1B mRNA in INR1G9 cells. (d) In situ hybridisation of TCPTP in mRNA INR1G9 cells.

cells had been subjected for $48 \mathrm{~h}$. Subsequently, the medium was replaced for glucagon determinations, and the cells were incubated for another $30 \mathrm{~min}$, as described in Materials and Methods. There was an obvious relationship between the vanadate concentration in the culture medium and the rate of glucagon release. Glucagon secretion increased to $615 \mathrm{ng} / 30 \mathrm{~min}$ per $10^{6}$ cells in the presence of $33 \mu \mathrm{M}$ vanadate in the medium compared to $6 \mathrm{ng} / 30 \mathrm{~min}$ per $10^{6}$ cells in untreated controls. Figure $6 \mathrm{~b}$ depicts the tyrosine phosphatase activities determined in extracts of the cells from the same series of experiments. Apparently, there was an inverse relationship between cellular phosphatase activity and vanadate concentration in the culture medium. As shown by the inset in Fig. 6b, the rate of glucagon secretion of INR1G9 cells was well correlated with the reciprocal of cellular tyrosine phosphatase activity (correlation coefficient $r=0 \cdot 95$ ).

As demonstrated by the experiment depicted in Fig. 7, the effect of $10 \mu \mathrm{M}$ vanadate on tyrosine phosphatase activity in INR1G9 cells was fully reversed to the value of untreated cells by removing vanadate from the incubation medium. Tyrosine phosphatase of cells remained constant during the first $48 \mathrm{~h}$ of incubation in the absence of vanadate and gradually decreased by $28 \%$ during another $48 \mathrm{~h}$ of incubation. In the presence of vanadate, however, the tyrosine phosphatase activity decreased by $66 \%$ during the first 48 -h period but returned to the values of control cells during a second 48-h period of incubation after removal of vanadate.

Rescue of PTP activity from vanadate inhibition by dithiothreitol (Huyer et al. 1997) also reversed the effect of 

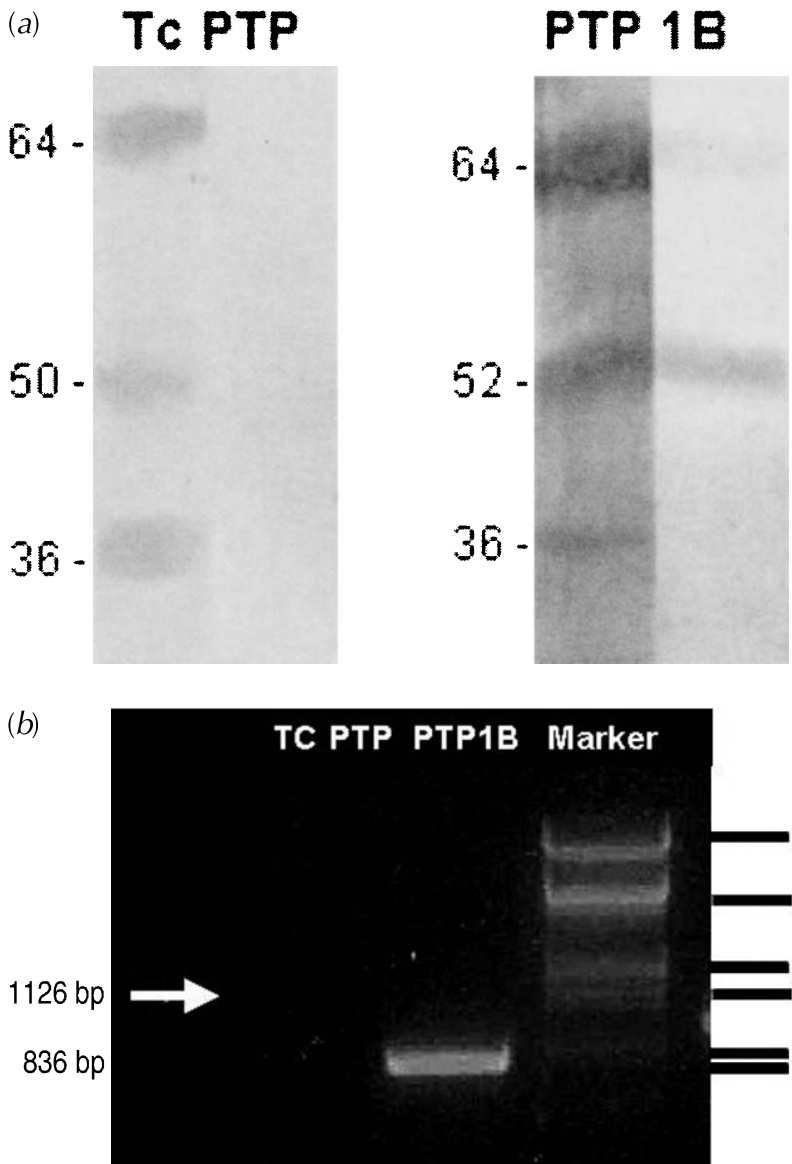

Figure 5 (a) Immunoblots of extracts of INR1G9 cells probed with monoclonal antibodies against PTP1B (right) and TCPTP (left) (see Materials and Methods for details). (b) RT-PCR of mRNA prepared from INR1G9 cells using Pfu-polymerase and primers for the conserved regions of PTP1B and TCPTP (see Materials and Methods for details). Markers (MBI Fermentas): M: $\lambda$ DNA EcoRI/HindIII. The positions indicated at the right side correspond to the following sizes (from top): 21 226, 4973, 2027, 1584, 947 and $831 \mathrm{bp}$. The arrow indicates the expected position of a PCR product encoding TCPTP (1126 bp, lane empty). The PCR product encoding PTP1B visible at the expected position (836 bp) corresponded to its predicted size. Reactions for mRNA of PTP1C and PTP1D were negative.

vanadate on glucagon secretion. Incubation of cells in the presence of $10 \mu \mathrm{M}$ vanadate led to an increase in glucagon secretion to $622 \mathrm{ng} / 30 \mathrm{~min}$ per $10^{6}$ cells and to a decrease in PTP activity to $1.8 \mathrm{nmol} / \mathrm{min}$ per $\mathrm{mg}$. Subsequent addition of $1 \mu \mathrm{M}$ DTT reduced the secretion rate to $18.5 \mathrm{ng} / 30 \mathrm{~min}$ per $10^{6}$ cells and increased the activity to $6.5 \mathrm{nmol} / \mathrm{min}$ per $\mathrm{mg}$. Moreover, inhibitors of PTP activity other than vanadate also led to increased glucagon secretion by INR1G9 cells. A 4-h incubation of cells with $50 \mu \mathrm{M}$ phenylarsine oxide (Zhang et al. 1992) reduced PTP activity to $10 \%$ of the control with a concomitant 22 -fold increase in glucagon release. $\mathrm{N}$-Ethylmaleimide, a
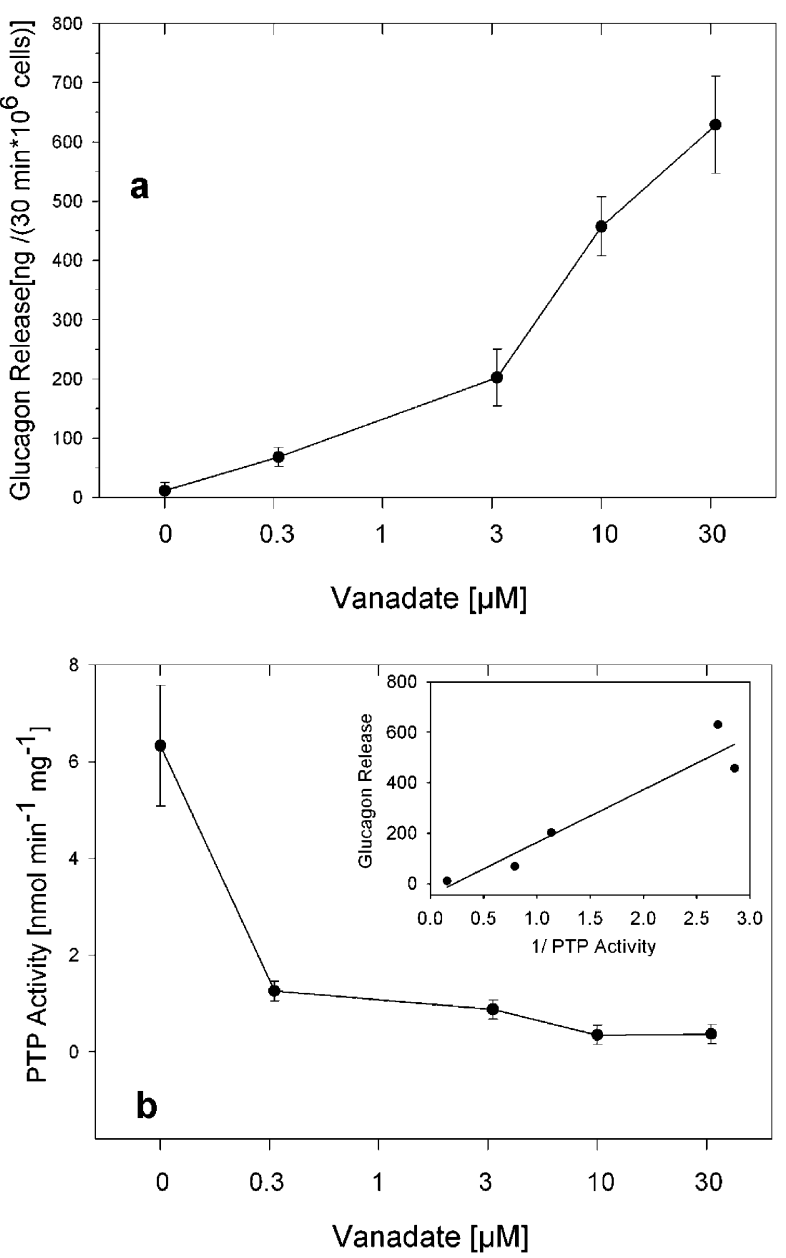

Figure 6 (a) Rate of glucagon secretion by INR1G9 cells treated with various concentrations of vanadate for $48 \mathrm{~h}$. Experimental procedures as described in Materials and Methods. (b) PTP activity in cellular extracts obtained from the cells of the same series of experiments shown in panel a. Inset: correlation between the rate of glucagon secretion shown in panel a and the reciprocals of the tyrosine phosphatase activities depicted in panel b. The regression line indicates an almost inverse relationship between secretion rate and tyrosine phosphatase activity $(r=0.95)$.

non-specific thiol reagent that efficiently blocks the highly reactive cysteine residue in the active centre of PTP (Pot \& Dixon 1992), also stimulated glucagon secretion. Concentrations of 1,50 and $100 \mu \mathrm{M}$ reduced PTP activity to $26 \%, 8 \%$ and $0 \%$ respectively of that in the control cells, while glucagon release increased 1.8-, 4.9- and 350-fold. As shown in Fig. 8, there was an immediate onset of the stimulating effect of vanadate on glucagon secretion by INR1G9 cells, with an approximately fivefold increase in the secretion rate within the first hour. Maximum secretion was observed about $40-50 \mathrm{~h}$ after the addition of vanadate. The presence of vanadate in cultures of INR1G9 cells reduced transcription of PTP1B mRNA. 


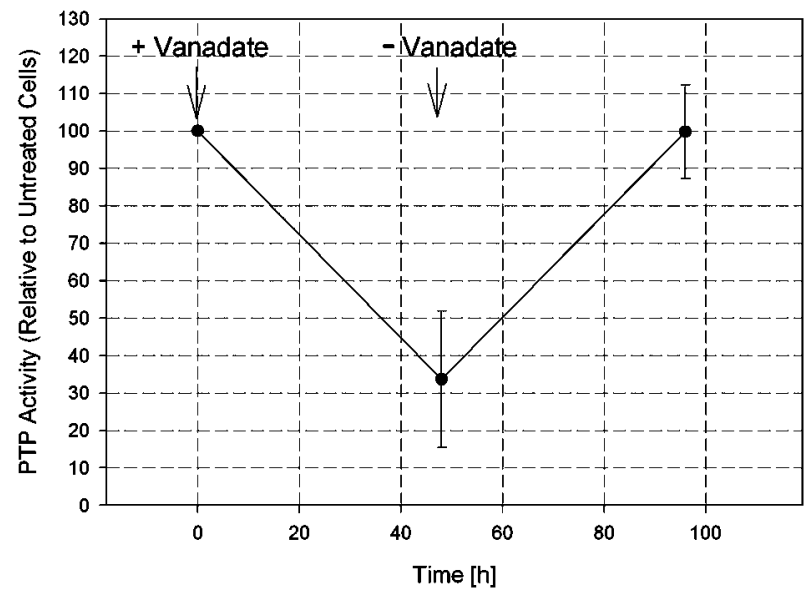

Figure 7 Rescue of tyrosine phosphatase activity in vanadate-treated INR1G9 cells. Tyrosine phosphatase activity measured in cells treated with $10 \mu \mathrm{M}$ vanadate for 48 decreased from $6 \cdot 24 \mathrm{nmol} \mathrm{min}^{-1} / \mathrm{mg}$ protein to $2 \cdot 10 \mathrm{nmol} \mathrm{min}^{-1} / \mathrm{mg}$ protein whereas the activity in control cells remained constant with $\pm 5 \%$. When the vanadate-containing medium was replaced by vanadate-free medium, the tyrosine phosphatase activity determined after a second $48 \mathrm{~h}$ period was the same $\left(4.48 \mathrm{nmol} \mathrm{min}^{-1} / \mathrm{mg}\right.$ cells $)$ as assayed in control cells cultured for $96 \mathrm{~h}$.

The result of quantitative evaluation of Northern blots is depicted in Fig. 9. A transcript of $3 \cdot 1 \mathrm{~kb}$ size was identified on the blots, and the signal persisted through highstringency washings. The intensity of the band from cells incubated with $10 \mu \mathrm{M}$ vanadate for $48 \mathrm{~h}$ was only $38 \%$ of that of untreated cells when referred to the same amount of ribosomal 18S RNA. Removal of vanadate and growth in normal medium for another $48 \mathrm{~h}$ led to a recovery of mRNA to $94 \%$ of the mRNA level of cells grown for $48 \mathrm{~h}$ in the absence of vanadate, corresponding to an increase in mRNA concentration by almost $250 \%$, although the

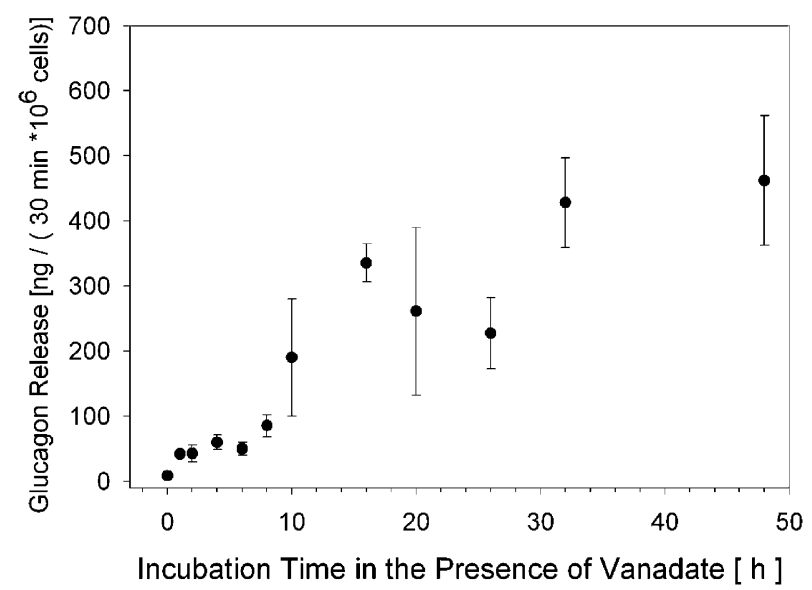

Figure 8 Dependence on incubation time of the effect of $10 \mu \mathrm{M}$ vanadate on the glucagon secretion of INR1G9 cells. Experimental procedures as described in Materials and Methods. intensity of the band was still somewhat less than that from cells grown in the absence of vanadate for $96 \mathrm{~h}$. The concentrations of mRNA transcripts of PTP1B in the presence of vanadate, therefore, changed in a similar manner as PTP activity. The signal of TCPTP on the Northern blots was too weak to allow determination of its quantity. PTP1C (synonym SHPTP1) and PTP1D (synonym: SHPTP2) showed no detectable hybridisation.

\section{Discussion}

Glucagon-secreting INR1G9 cells show intensive immunoreaction with a polyclonal antiserum raised against the conserved moiety of the PTP1B/TCPTP subfamily of PTP in a manner similar to that previously observed in A cells of Langerhans islets (Wimmer et al. 1999). Most of the immunoreactive tyrosine phosphatase was located on secretory granules and co-localised with synaptophysin, an integral membrane glycoprotein of secretory vesicles in endocrine pancreas (Kalina et al. 1991, Redecker et al. 1991). The polyclonal antibodies used for these immunocytochemical studies recognised both members of the PTP1B/TCPTP subfamily of PTP. Yet, solely monoclonal antibodies against PTP1B showed a positive reaction on immunoblots of SDS-PAGE of cell extracts. The preponderance of PTP1B over TCPTP in INR1G9 cells was also supported by experiments that proved the presence of specific mRNA (RT-PCR, in situ hybridisation, Northern blots), whereas none of these assays were positive for TCPTP.

This was in agreement with the signals obtained on Western blots using the same monoclonal antibodies. The PTP inhibitor vanadate led to a concentration-dependent 100-fold increase of glucagon release by INR1G9 cells. Vanadate is known as a kinetic inhibitor of PTP1B binding to the catalytic centre of the enzyme (Barford et al. 1994), but it may also exert other actions in cells. Distinct stimulation of glucagon secretion has already been observed in the presence of $0 \cdot 3 \mu \mathrm{M}$ vanadate in the medium, a concentration only slightly inhibiting PTP activity in vitro. Although there was a rapid onset of the stimulation of glucagon secretion following the addition of vanadate, the maximum effect was visible only after about 2 days. Vanadate also reduced PTP activity in cell extracts when assessed by an assay which preferentially detected PTP of the PTP1B/TCPTP subfamily. The reduction of tyrosine phosphatase activity in INR1G9 cells was reversed by the removal of vanadate and by addition of dithiothreitol. The vanadate effect was possibly due to reduced expression of $\mathrm{PTP} 1 \mathrm{~B}$ protein, since the vanadate concentrations present in the activity assays were very low and unable to account for the observed reduction of phosphatase activity. This view is corroborated by the reduced levels of PTP1B mRNA after treatment with vanadate and its recovery after vanadate removal. The 


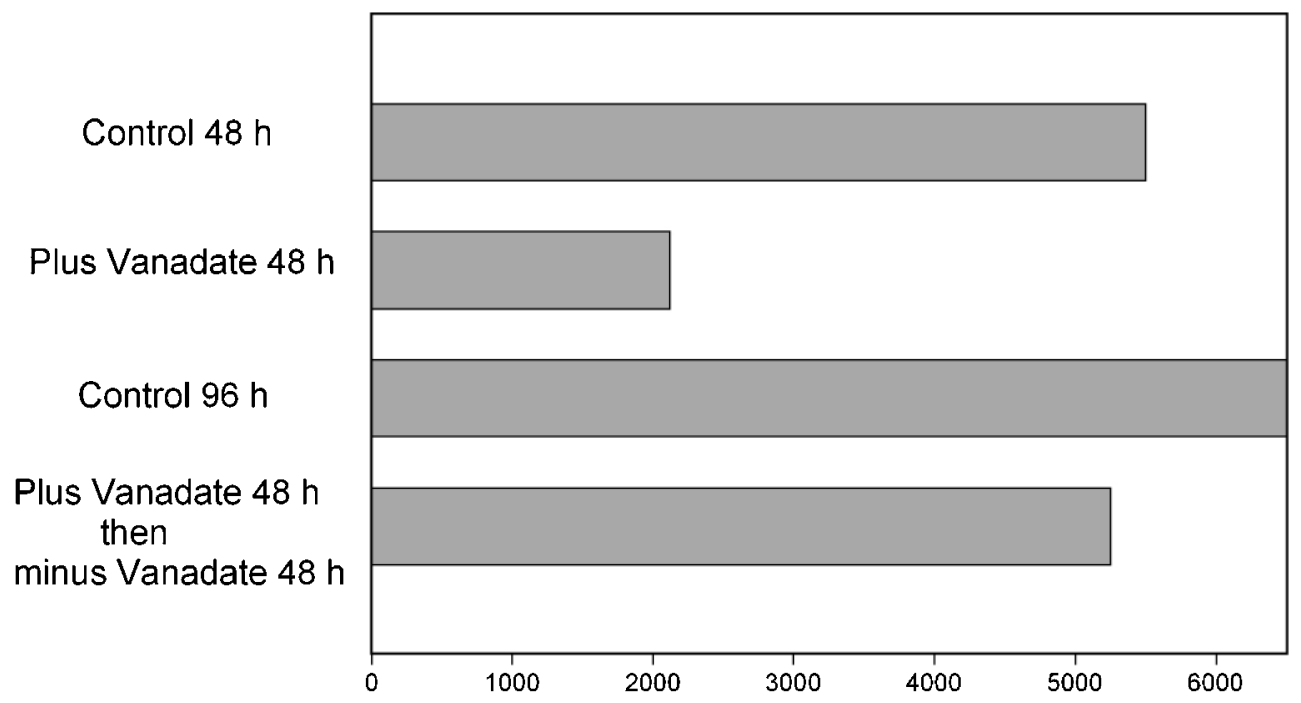

Hybridisation Signal (relative units)

Figure 9 Changes in PTP1B mRNA levels in INR77701G9 cells upon treatment with vanadate. An experiment similar to that described in Fig. 7 was conducted in the presence and absence of vanadate, and RNA was prepared from the cells. Northern blots were evaluated by luminescence with a digoxigenin-labelled probe for PTP1B mRNA and $\alpha$-digoxigenin coupled to alkaline phosphatase. The blots were scanned and the intensity of bands was evaluated as described in Materials and Methods. The data represent two experiments.

mechanism of the influence of vanadate on the transcription of PTP1B mRNA is unknown at present; however, a similar effect has been previously observed in lymphocytes (R Simpfendorfer \& H W Hofer, unpublished).

It should be emphasised that stimulation of glucagon secretion was not a transient or short-term effect and was unlikely to be due to vanadate-induced overall damage of cellular function, since the cells were cultivated in the presence of vanadate for 2 days before the rate of glucagon secretion was measured. Therefore, the cells under study must have been fully in balance with the effects of the inhibitor after $48 \mathrm{~h}$ of exposure. The enhancement of glucagon release in response to vanadate under the steadystate conditions of our experiments, therefore, suggests a direct influence of vanadate on secretion rather than a secretory burst potentially caused indirectly by the interference of vanadate with other cellular functions. The inverse relationship between the effect of increasing vanadate concentrations on glucagon secretion and the effect on tyrosine phosphatase activity in the cells suggests a link between the depletion of phosphatase and elevated secretion. One reason to prefer the use of the potentially less specific vanadate to the unstable, but more specific and putatively irreversible, tyrosine phosphatase inhibitor pervanadate (Fantus et al. 1989) was to avoid the possibility of acute but transient toxicity and to establish steady-state conditions under which the inhibitor was expected to create a stable response of the cells - that is, a persistent increase in the level of tyrosine phosphorylation due to reduced phosphatase activity. Since a large amount of PTP1B was found in contact with secretory vesicles, we hypothesise that its function is to prevent inappropriate secretion of glucagon by attenuating a secretory trigger mechanism or by inhibiting a key step of exocytosis.

In contrast to tyrosine-specific phosphatases, the involvement of serine/threonine phosphatases in the regulation of glucagon secretion was not supported by our experiments. Okadaic acid, a potent inhibitor of type 1 and type $2 \mathrm{~A}$ protein phosphatases, which led to increased or reduced secretion rates in other studies (Arufe et al. 1999, Matovcik et al. 1999, Sjoholm et al. 2002), had no influence on glucagon secretion by INR1G9 cells.

The proposed effect of PTP1B on secretory granules of glucagon-secreting A cells appears to be different from that proposed for the receptor-like PTP IAR, or phogrin, on insulin-producing B cells. These phosphatases were found to be activated by secretagogues (Cui et al. 1998). Loading of a recombinant PTP to permeabilised pancreatic acini also stimulated $\mathrm{Ca}^{2+}$-dependent amylase secretion (Jena et al. 1991). An opposite function of tyrosine phosphatase in amylase secretion, however, was indicated by the report that the increase in cytosolic paxillin-dephosphorylating tyrosine phosphatase activity caused by disruption of the actin cytoskeleton led to an inhibition of amylase secretion in a pancreatic acinar cell line (Feick et al. 1999). In agreement with this observation, treatment of the 
cells with pervanadate stimulated amylase release and phosphorylation of paxillin (Feick et al. 1998). Probably tyrosine phosphorylation is involved in more than one branch of the secretory pathway, and these pathways may even be subjected to variable regulatory mechanisms depending on the cell type. Nevertheless, the observations reported here suggest a suppressive effect of PTP1B on the release of glucagon and an important role of the enzyme in the regulation of glucagon secretion.

\section{Acknowledgements}

We are indebted to Prof. Ryosaburo Takaki and Dr Hamaguchi (Department of Internal Medicine I, Oita Medical University, Oita, Japan) and to Dr U Wulbrand (Department of Medicine, Philipps University, Marburg, Germany) for the gift of INR1G9 cells; to Martin Bodenbenner (University of Giessen, Giessen, Germany) for help with cell cultures; and to Martina Birk (University of Konstanz, Konstanz, Germany) for technical assistance. The project was supported by the Deutsche Forschungsgemeinschaft (grant no. 650/7) to $\mathrm{H} \mathrm{W} \mathrm{H.}$

\section{References}

Arufe MC, Beckett GJ, Duran R \& Alfonso M 1999 Effect of okadaic acid and calyculin-A, two protein phosphatase inhibitors, on thyrotropin-stimulated triiodothyronine secretion in cultured sheep thyroid cells. Endocrine 11 235-240.

Barford D, Flint AJ \& Tonks NK 1994 Crystal structure of human protein tyrosine phosphatase 1B. Science 263 1397-1404.

Batzer A, Kirsch S \& Hofer HW 1990 Characterization of two tyrosine-specific protein kinases from pig spleen. Substrate-specific effect of autophosphorylation. European Journal of Biochemistry 194 251-258.

Bode HP, Yule DI, Fehmann HC, Goke B \& Williams JA 1994 Spontaneous calcium oscillations in clonal endocrine pancreatic glucagon-secreting cells. Biochemical and Biophysical Research Communications 205 435-440.

Bode HP, Weber S, Fehmann HC \& Goke B 1999 A nutrient-regulated cytosolic calcium oscillator in endocrine pancreatic glucagon-secreting cells. Pflugers Archiv 437 324-334.

Cohen P 1989 The structure and regulation of protein phosphatases. Annual Review of Biochemistry 58 453-508.

Cohen P, Holmes CF \& Tsukitani Y 1990 Okadaic acid: a new probe for the study of cellular regulation. Trends in Biochemical Sciences $\mathbf{1 5}$ 98-102.

Cool DE, Tonks NK, Charbonneau H, Walsh KA, Fischer EH \& Krebs EG 1989 A cDNA isolated from human T-cell library encodes a member of the protein-tyrosine phosphatase family. PNAS 86 5257-5261.

Cui L, Yu WP \& Pallen CJ 1998 Insulin secretagogues activate the secretory granule receptor-like protein-tyrosine phosphatase IAR. Journal of Biological Chemistry 273 34784-34791.

Dhanvantari S \& Brubaker PL 1998 Proglucagon processing in an islet cell line: effects of PC1 overexpression and PC2 depletion. Endocrinology 139 1630-1637.

Dirkx R Jr, Hermle JM, Rabin DU \& Solimena M 1998 ICA 512, a receptor tyrosine phosphatase-like protein, is concentrated in neurosecretory granule membranes. Advances in Pharmacology 42 243-246.
Drucker DJ, Philippe J \& Mojsov S 1988 Proglucagon gene expression and posttranslational processing in a hamster islet cell line. Endocrinology 123 1861-1867.

Fantus IG, Kadota S, Deragon G, Foser B \& Posner BI 1989 Pervanadate [peroxide(s) of vanadate] mimics insulin action in rat adipocytes via activation of the insulin receptor tyrosine kinase. Biochemistry 28 8864-8871.

Feick P, Gilhaus S \& Schulz I 1998 Pervanadate stimulates amylase release and protein tyrosine phosphorylation of paxillin and p125(FAK) in differentiated AR4-2J pancreatic acinar cells. Journal of Biological Chemistry 273 16366-16373.

Feick P, Gilhaus S, Blum R, Hofmann F, Just I \& Schulz I 1999 Inhibition of amylase secretion from differentiated AR4-2J pancreatic acinar cells by an actin cytoskeleton controlled protein tyrosine phosphatase activity. FEBS Letters 451 269-274.

Gogg S, Chen J, Efendic S, Smith U \& Ostenson C 2001 Effects of phosphotyrosine phosphatase inhibition on insulin secretion and intracellular siganling events in rat pancreatic islets. Biochemical and Biophysical Research Communications 280 1161-1168.

Huyer G, Liu S, Kelly J, Moffat J, Payette P, Kennedy B, Tsaprailis G, Gresser MJ \& Ramachandran C 1997 Mechanism of inhibition of protein-tyrosine phosphatases by vanadate and pervanadate. Journal of Biological Chemistry 272 843-851.

Jena BP, Padfield PJ, Ingebritsen TS \& Jamieson JD 1991 Protein tyrosine phosphatase stimulates $\mathrm{Ca}^{2+}$-dependent amylase secretion from pancreatic acini. Journal of Biological Chemistry 266 17744-17746.

Kalina M, Lukinius A, Grimelius L, Hoog A \& Falkner S 1991 Ultrastructural localization of synaptophysin to the secretory granules of normal glucagon and insulin cells in human islets of Langerhans. Ultrastructural Pathology 15 215-219.

Kawasaki E, Hutton JC \& Eisenbarth GS 1996 Molecular cloning and characterization of the human transmembrane proteintyrosine phosphatase homologue, phogrin, an autoantigen of type 1 diabetes. Biochemical and Biophysical Research Communications 227 440-447.

Lehrach H, Diamond D, Wozney JM \& Boedtker H 1977 RNA molecular weight determinations by gel electrophoresis under denaturing conditions, a critical re-examination. Biochemistry 16 4743-4751.

Marantz Y, Reiss N, Przedecki F \& Naor Z 1995 Involvement of protein phosphatases in gonadotropin releasing hormone regulated gonadotropin secretion. Molecular and Cellular Endocrinology 111 7-11.

Matovcik LM, Rhee SS, Schaefer JF, da Cruz e Silva EF \& Kinder BK 1999 Inhibition of protein phosphatase 1 decreases PTH secretion from isolated dispersed parathyroid cells. Molecular and Cellular Endocrinology 154 171-177.

Mineo I, Matsumura T, Shingu R, Namba M, Kuwajima M \& Matsuzawa Y 1995 The role of prohormone convertases PC1 (PC3) and PC2 in the cell-specific processing of proglucagon. Biochemical and Biophysical Research Communications 207 646-651.

Ort T, Voronov S, Guo J, Zawalich K, Froehner SC, Zawalich W \& Solimena M 2001 Dephosphorylation of beta2-syntrophin and $\mathrm{Ca}^{2+} / \mathrm{mu}$-calpain-mediated cleavage of ICA512 upon stimulation of insulin secretion. EMBO Journal 20 4013-4023.

Payton MA, Hawkes CJ \& Christie MR 1996 Relationship of the 35,000- and 40,000- $M_{\mathrm{r}}$ tryptic fragments of islet antigens in insulin-dependent diabetes to the protein tyrosine phosphatase-like molecule IA-2(ICA512). Journal of Clinical Investigation 96 1506-1511.

Pietropaolo M, Hutton JC \& Eisenbarth GS 1997 Protein tyrosine phosphatase-like proteins: link with IDDM. Diabetes Care $\mathbf{2 0}$ 208-214.

Pot DA \& Dixon JE 1992 Active site labeling of a receptor-like protein tyrosine phosphatase. Journal of Biological Chemistry 267 140-143. 
Redecker P, Jörns A, Jahn R \& Grube D 1991 Synaptophysin immunoreactivity in the mammalian endocrine pancreas. Cell Tissue Research 264 461-467.

Schmid B, Wimmer M, Tag C, Hoffmann R \& Hofer HW 1996 Protein phosphotyrosine phosphatases in Ascaris suum muscle. Molecular and Biochemical Parasitology 77 183-192.

Sjoholm A, Lehtihet M, Efanov AM, Zaitsev SV, Berggren PO \& Honkanan RE 2002 Glucose metabolites inhibit protein phosphatases and directly promote insulin exocytosis in pancreatic beta-cells. Endocrinology 143 4592-4598.

Takaki R, Ono J, Yokogawa Y, Kumae S, Hiraoka T, Yamaguchi K, Hamaguchi K \& Uchida S 1986 Isolation of glucagon-secreting cell lines by cloning insulinoma cells. Cell and Developmental Biology 22 120-126.

Tonks NK, Diltz CD \& Fischer EH 1988 Purification of protein-tyrosine phosphatases from human placenta. Journal of Biological Chemistry 263 6722-6730.

Towbin H, Staehelin T \& Gordon J 1979 Electrophoretic transfer of proteins from polyacrylamide gels to nitrocellulose sheets: procedure and some applications. PNAS 76 4350-4354.

Wasmeier C \& Hutton JC 1999 Secretagogue-dependent phosphorylation of phogrin, an insulin granule membrane protein tyrosine phosphatase homologue. Biochemical Journal 341 563-569.

Wasmeier C \& Hutton JC 2001 Secretagogue-dependent phosphorylation of the insulin granule memrane protein phogrin is mediated by cAMP-dependent protein kinase. Journal of Biological Chemistry 276 31919-31928.
Wasmeier C, Bright NA \& Hutton JC 2002 The luminal domain of the integral membrane protein phogrin mediates targeting to secretory granules. Traffic 3 654-665.

Wimmer M, Schmid B, Tag C \& Hofer HW 1998 Ascaris suum: protein phosphotyrosine phosphatases in oocytes and developing stages. Experimental Parasitology 88 139-145.

Wimmer M, Tag C \& Hofer HW 1999 A non-receptor-type protein phosphotyrosine phosphatase is enriched in secretory vesicles of glucagon - and pancreatic polypeptide - secreting cells of the endocrine pancreas. Histochemistry and Cell Biology 1 135-142.

Voges A 2003 Protein tyrosine phosphatases from spleen: Purification and characterisation. PhD Thesis. University of Konstanz.

Zanone MM, Catalfamo E, Pietropaolo SI, Rabbone I, Sacchetti C Cerutti F, Trucco M \& Cavallo-Perin P 2003 Glutamic acid decarboxylase and ICA512/IA-2 autoantibodies as disease markers and relationship to residual beta-cell function and glycemic control in young type I diabetic patients. Metabolism 52 25-29.

Zhang ZY, Davis JP \& Van Etten RL 1992 Covalent modification and active site-directed inactivation of a low molecular weight phosphotyrosyl protein phosphatase. Biochemistry 31 1701-1711.

Received 19 December 2003

Accepted 9 March 2004

Made available online as an

Accepted Preprint 16 March 2004 